\title{
International Migration, Transfers of Norms and Home Country Fertility
}

M. Beine, F. Docquier and M. Schiff

Discussion Paper 2008-43

Département des Sciences Économiques

de l'Université catholique de Louvain 


\title{
International Migration, Transfers of Norms and Home Country Fertility*
}

\author{
Michel Beine ${ }^{a}$, Frédéric Docquier ${ }^{b}$ and Maurice Schiff $^{c}$ \\ ${ }^{a}$ University of Luxemburg and CES-Ifo \\ ${ }^{b}$ FNRS and IRES, Université Catholique de Louvain, IZA-Bonn and CReAM-London \\ ${ }^{c}$ World Bank, University of Chile, and IZA-Bonn
}

December 2008

\begin{abstract}
This paper examines the relationship between international migration and source country fertility. The impact of international migration on source country fertility may have a number of causes, including a transfer of destination countries' fertility norms and an incentive to acquire more education. We provide a rigorous test of the diffusion of fertility norms using original and detailed data on migration. Our results provide evidence of a strong transfer of fertility norms from migrants to their country of origin.
\end{abstract}

JEL classification: J13, J61, O11.

Keywords: International migration, endogenous fertility, human capital, social norms.

\section{Introduction}

With population forecasts indicating rapid population growth in developing countries and slow growth in developed ones, international migration is likely to continue to play an (increasingly) important role in the global economy. A world of rapid population

${ }^{*}$ This paper was written while Michel Beine was visiting the World Bank, DECRG Trade Unit. Thanks are due to Chris Parsons for providing us with the data and to Caglar Ozden and Ramón Lopez for their useful comments. The views in this paper are those of the authors and do not necessarily reflect those of their respective institutions, the World Bank Executive Directors and the governments they represent. The second author acknowledges financial support from the Belgian Federal Government (PAI grant P6/07 Economic Policy and Finance in the Global Equilibrium Analysis and Social Evaluation) and from the Marie-Curie research and training network TOM (Transnationality of migrants). 
growth and increasing pressure on natural resources would greatly benefit from SouthNorth migration if the latter resulted in a reduction in source countries' fertility rates.

Migration may affect the fertility of migrants living in the host country, of mi.grants' households back home, and of the home country population as a whole. This paper focuses on the latter, that is, on the impact of migration on the fertility of the population in migrants' country of origin. It presents a theoretical model and empirically tests the model's predictions. Our main finding is that international migration results in a transfer of behavioral norms regarding fertility from host to migrants' home countries, resulting in a decrease (increase) in home country fertility rates if they are higher (lower) than host country rates. The literature has so far not provided any robust evidence of migration externalities through the transfer of behavioral norms to host countries. An exception is Spilimbergo (2008) who shows that foreign-trained individuals promote democracy in their home countries, but only if foreign education is acquired in democratic countries. Here we use a similar conceptual framework and show that it also matters for fertility behavior.

The paper is organized as follows. Section 2 presents a selected review of the literature on the impact of migration on fertility rates in the three groups mentioned above. Section 3 develops a theoretical model where alternative hypotheses regarding the impact of international migration on source country fertility are examined. Section 4 presents the econometric specification, describes data sources and reports the empirical results. Section 5 concludes.

\section{Selected Literature Review}

A necessary condition for migration to result in source countries' adoption of host countries' behavioral norms is that they can be adopted by the migrants themselves. Similarly, one would expect these norms to be adopted by migrant households since they would most likely obtain the relevant information on host countries' norms before the rest of the home country population, and in a more direct and detailed manner. Examining what the literature says about migration's impact on the fertility of both migrants and home country migrant households is thus important for understanding whether and through what channels migration impacts source country fertility. Studies on the impact on migrants and migrant households are reviewed in Section 2.1, and on the source country population in Section 2.2.

\subsection{Fertility Impact on Migrants and Migrant Households}

The bulk of the research has dealt with migration's impact on migrants' fertility. Several hypotheses have been examined in this literature, including socialization, adaptation, and selection. ${ }^{1}$ According to the socialization hypothesis, migrants are

\footnotetext{
${ }^{1} \mathrm{~A}$ fourth hypothesis is that of disruption whereby migrants show low fertility levels immediately following migration. However, this hypothesis does not tell us much if anything about migration's
} 
socialized by early childhood experiences and post-migration fertility levels remain similar to those in source areas or countries. Early studies on US internal migration find support for this hypothesis, with Goldberg $(1959,1960)$ and Freedman and Slesinger (1961) showing that rural-urban migrants exhibit higher fertility rates than urban natives. However, they do not examine changes in migrants' fertility rates over time. Moreover, findings of later studies are generally consistent with the adaptation rather than the socialization hypothesis.

According to the adaptation hypothesis, the impact of host (home) country values and norms on migrants' behavior increases (decreases) with the length of the migration, with migrants' fertility rates converging to those of natives over time. This hypothesis has received wide support in the literature, both for internal (rural-urban) and international migration.

Internal migration studies that examine the fertility impact of rural-urban migration have found support for the convergence of migrants' fertility rates to those of natives. Studies on internal migration in developing countries include Myers and Morris (1966) on Puerto Rico, Goldstein (1973) on Thailand, Martine (1975) on Colombia, Park and Park (1976) on Costa Rica, Hiday (1978) on the Philippines, Faber and Lee (1984) on Korea, Hervitz (1985) on Brazil, Lee and Pol (1993) on Mexico, Brockeroff (1995) on thirteen African countries, Umezaki and Ohtsuka (1998) on Papua New Guinea and Kulu (2003) on Estonia. Convergence results are also obtained in studies of international migration, including Stephen and Bean (1992) and Lindstrom and Giorguli Saucedo (2002) for women of Mexican origin living in the US.

Convergence of migrants' fertility rates might be due to selection rather than adaptation. Migrants do not constitute a random sample of the home population and they might exhibit lower fertility rates than the overall population. The studies described above do not control for potential selection effects, with some finding that selection effects played an important role in explaining the change in fertility associated with migration, while others did not or found that the presence or absence of selection effects depends on the type of migration examined. Studies by Goldstein (1973), Hervitz (1985) and Kulu (2003) examined the various hypotheses and found strong support for the adaptation rather than the selection hypothesis, though White et al.'s (1995) found limited support for the latter in a study on internal migrants in Peru. ${ }^{2}$

The impact of migration on the fertility of households back home has also been analyzed, though by a much smaller number of studies. One hypothesis examined is that the influence of host countries' fertility norms persists after migrants return home and thus results in a decrease in fertility. For instance, Lindstrom and Giorguli Saucedo (2002) find that Mexico-US temporary migration of women reduces longterm household fertility. Another hypothesis is that migration reduces fertility while the migrant is away and raises it when the migrant returns, a hypothesis confirmed in

impact on completed (lifetime) fertility, which is the subject of this paper.

${ }^{2}$ They find that education and having fewer children are positively related to geographic mobility. 
the case of male migration (e.g., Hervitz 1985). The results have been interpreted as being due to interruption and catching up of fertility, with no clear long-term fertility impact.

Lindstrom and Muñoz-Franco (2005) examine the impact of migration on women's modern contraceptive knowledge and use - and thus on their fertility - in rural Guatemala. They find that contraceptive use increases and fertility falls with variables such as having family members in urban or international destinations, living in a community where urban migration is common, having social ties to urban or international migrants, and having an urban migration experience. They also find that these variables become non-significant once they control for their knowledge-diffusion impact, concluding that it is through the knowledge acquired from urban migration experiences, contacts with urban or international migrants, or living in a community where such migration is prevalent, that contraceptive knowledge and use increases and fertility declines.

Thus, most studies on migration's fertility impact have confirmed that migration to low-fertility countries (regions) reduces migrants' fertility in the home country (region), and that the reduction in fertility is due to adaptation of migrants' fertility behavior to the norms of the host countries (regions). The studies also obtain similar results with respect to home countries' migrant household fertility behavior. Moreover, the latter are associated with a transfer of norms from the host country or region to the migrant household or community, either because of return migration or because of information obtained from migrants.

\subsection{Fertility Impact on Home Country Population}

Another question is whether migration results in a change in fertility rates of the population in migrants' countries of origin. Since migrants' behavioral norms tend to converge to those of their host countries, it is not unreasonable to assume that migrants might serve as channels for the transmission of such norms and might affect the behavior of natives in their countries of origin, including their fertility behavior. In such a case, the positive spillover effect of migration in terms of reduced population pressure would be vastly greater than if the decline in fertility rates only affected the migrants.

It is important to note that the impact of international migration on fertility rates in migrants' home country may operate through several channels. The first channel consists of migrants' direct communication with their family, friends and community. Second, migration typically triggers an increase in interest by source countries' population about the situation in host countries as well as that of their country's migrants living there. This tends to be reflected, inter alia, in an increase in media coverage of both the host country and of the migrants living there.

Third, media attention is also likely to focus on the situation of return migrants, including their economic performance, views and behavioral modes, and how they 
might differ from those of natives. Fourth, a number of studies have found that migration and migrant networks result in increased trade between host and source countries (Gould 1994, Rauch 2001, Rauch and Trindade 2002) and in increased investment from the former to the latter (Kugler and Rapoport 2006, Javorcik et al., 2006). Thus, increased business-related contacts with migrants' host countries is likely to constitute another channel through which the latter' norms are diffused to source countries' natives. Finally, fertility and other behavioral norms that are diffused through these various channels are likely to be further diffused to those who do not have direct access to them through word-of-mouth. ${ }^{3}$

The issue of international migration as a channel for the diffusion of fertility norms has not been systematically studied. The only research we are aware of that examines the link between international migration and source country fertility is Fargues (2007). His analysis is based on fertility behavior in three source countries, namely Morocco, Turkey and Egypt. Migration from Morocco and Turkey over the period 1960-2000 was essentially to the low-fertility countries of Western Europe while that of Egypt was essentially to the high-fertility countries of the Persian Gulf. Fargues shows that fertility rates in these countries were affected by the rates prevailing in their migrants' host countries, with rates declining in Morocco and Turkey and increasing in Egypt. He also finds that the degree to which the demographic transition has been attained increases with migration rates across regions of Morocco and Turkey and decreases with migration rates across regions of Egypt.

Fargues posits that the impact of host countries' fertility rates on those in migrants' home countries is due to the transfer of behavioral norms from host to source country. However, he does not subject his hypothesis to rigorous testing or consider alternative ones. ${ }^{4}$

This paper provides a rigorous econometric analysis of the relationship between international migration and source country fertility. The impact of the former on the latter may have a number of causes, one of which is the transfer of host country fertility norms. These causes are examined theoretically and the hypotheses derived from the model are tested empirically. The econometric analysis is based on a new database of international bilateral migration for the year 2000 (Parsons et al. 2007) that covers all countries and territories. We find that fertility in migrants' home countries decreases (increases) in the case where it is higher (lower) than fertility in the host countries.

\footnotetext{
${ }^{3}$ Those with direct access to information on fertility norms in host countries or to returning or visiting migrants may learn about them indirectly through others who do have direct access to such information.

${ }^{4}$ Ebanks et al. (1975) for Barbados and Lee and Farber (1985) for Korea compute the impact of migration on fertility in the home country. However, their calculations are unrelated to the impact of migration on fertility behavior back home. Rather, they calculate what the fertility in the home country would have been had migrants stayed home by assuming that migrants' fertility rates are equal to those of observably similar non-migrants.
} 


\section{Theory}

As South-North migration can affect fertility decisions in the South through multiple channels, assessing the effect of diffusions of norms requires controlling for the other mechanisms at work. A stylized theoretical model is helpful to derive testable predictions.

The main mechanisms we envisage here are the following. By affecting the expected return to higher education, migration prospects impact on adults' human capital investments, which in turn, determine the opportunity cost of raising children. As a more educated child has a higher probability to emigrate to a rich country, expectations about offspring migration impact on the 'quantity-quality' tradeoff. Through remittances, past migrations impact on adults' income and affects the demand for children. Let us first describe the general model including all these mechanisms and then solve different variants of the model focusing on each particular channel. Each variant generates specific testable predictions which should be accounted for in our empirical analysis.

We consider an overlapping generations economy populated by two-period lived agents (adult and children). Following De la Croix and Doepke (2003, 2004), Galor and Mountford (2006), Moav (2005) or Mountford and Rapoport (2007), adults' utility function has two arguments, the amount of consumption and the total expected income of children. The second component of the utility function reflects parental altruism but it could also be compatible with the fact that parents care about old-age security if children transfer money to their parents when the latter retire. We have

$$
U_{t}=\log \left(c_{t}\right)+\beta \log \left(\widetilde{w}_{t+1} h_{t+1} n_{t}\right)
$$

where $c_{t}$ denotes parent's consumption, $n_{t}$ is the number of children (fertility), $h_{t+1}$ is the human capital of each child and $\widetilde{w}_{t+1}$ is the expected wage per efficiency unit of labor of children. Uncertainty about future children wages arises from the fact that children may stay in their origin country or emigrate to a richer country.

Adults are endowed with one unit of time that they can spend in supplying labor, raising children or investing in their own education. Raising each child requires $\phi$ units of time. Given their inherited level of human capital $h_{t}$ (resulting from their own parents' decisions), adults may spend a fraction $E_{t}$ of their time in higher education to increase their human capital. The training technology is given by

$$
H_{t}=\Theta\left(E_{t}, h_{t}\right)
$$

such that $\Theta_{E}^{\prime}, \Theta_{h}^{\prime} \geq 0$. In the next sub-sections, we will consider variants where $\Theta($. has a Cobb-Douglas analytical form and variants disregarding parents human capital decisions, $\Theta\left(E_{t}, h_{t}\right)=h_{t}$.

Parents can also invest in the human capital of their offspring. Investing $e_{t}$ dollars in children's basic education increases their human capital. We assume that

$$
h_{t+1}=\theta\left(e_{t}\right)
$$


where $\theta_{e}^{\prime} \geq 0$ and $\theta_{e}^{\prime} \leq 0$. In the next sub-sections, we will consider variants with $h_{t+1}=e_{t}^{\gamma}$ with $\gamma \in[0,1]$ and variants with exogenous education choices, $h_{t+1}=\bar{h}$.

The adult budget constraint is given by:

$$
c_{t}=\left(1-E_{t}-\phi n_{t}\right) w_{t} H_{t}-n_{t} e_{t}+r_{t}
$$

where $r_{t}$ stands for non labor income (including remittances received in adulthood) and $w_{t}$ denotes adult's wage.

Assuming that adult education arises before employment, adults are uncertain about their future place of work. If they stay in the South (with probability $p_{t}$ ), the wage rate is given by $w_{t}=w_{t}^{h}$. If they move to the North (with probability $1-p_{t}$ ), the wage rate becomes $w_{t}=w_{t}^{f}>w_{t}$. The production functions in the South and in the North are linear in labor (in efficiency unit). It implies that the local and foreign wage rates $w_{t}^{h}$ and $w_{t}^{f}$ are time invariant. Without loss of generality, $w_{t}^{h}$ can be normalized to unity and we can write $\omega=w^{f}-1$.

Adults are also uncertain about the place of work of their children. Children will become adult at time $t+1$ and will be able to emigrate with a probability $p_{t+1}$. The expected wage for each child in (1) is given by

$$
\widetilde{w}_{t+1}=p_{t+1} w^{f}+\left(1-p_{t+1}\right) w^{h}=1+p_{t+1} \omega
$$

The migration probability depends on country characteristics (such as geographical position, colonial links, linguistic proximity, etc.) and individual characteristics. In particular, it can be reasonably assumed that the probability increases in human capital. We have:

$$
p_{t}=p_{0} \cdot \pi\left(H_{t}\right)
$$

where $p_{0}$ captures country characteristics and $\pi\left(H_{t}\right)$, such that $\pi^{\prime} \geq 0$ and $\pi^{\prime \prime} \leq 0$, reflects the fact that educated agents have a higher probability to emigrate.

Let us now solve particular variants of this general model, based on particular analytical specifications for our technological functions $\Theta(),. \theta($.$) and \pi($.$) .$

\subsection{Fertility, migration and adults' higher education}

We first focus on the relationship between migration prospects and human capital formation, as stated in the new brain drain literature (Mountford, 1997, Beine et al., 2001 and 2008, or Docquier et al., 2008). To, address this issue, let us consider a simplified model in which children's human capital $\bar{h}$ is exogenous. Think about a mandatory education system totally subsidized by the government. The cost of education can therefore be removed from the budget constraint $\left(e_{t}=0\right)$. We also disregard remittances $\left(r_{t}=0\right)$.

Parents can invest $E_{t}$ in higher education to increase their productivity and their own probability to emigrate. After education, they will work abroad and earn a wage 
$w^{f}$ with a probability $p_{t}$. They will work at home and earn a wage equal to one with a probability $1-p_{t}$.

The timing is the following. First, parents decide whether or not to invest. Second, they emigrate or stay in their home country. Third, they work, have children and consume. Parents thus take tow decisions, $E_{t}$ and $n_{t}$. The choice of $E_{t}$ is made under uncertainty about the place of work.

Parents care about the expected income of their offspring. For mathematical tractability, we assume that the probability that a child will live abroad do not depend on parents' location. This implies that $\widetilde{w}_{t+1}$ is given in (1). Considering that children born abroad have a much higher probability to stay would induce parents to invest more in human capital. This would simply reinforce our mechanism. As $h_{t+1}$ is also exogenous, the second component of the utility function (1) only depends on the number of children, $n_{t}$.

The following specifications are used:

- Parents' probability to emigrate in (6) has a logarithmic form: $\pi()=.\log \left(H_{t}\right)$.

- Parents' productivity is endogenous and (2) has a Cobb Douglas form: $\Theta()=$. $A E_{t}^{\sigma} \bar{h}^{1-\sigma}$.

- Children's human capital in (3) is fixed: $\theta()=.\bar{h}$.

- remittances are nil: $r_{t}=0$.

In Appendix 7.1, we solve the model in two steps and proceed backwards. First, for a given location, parents choose their optimal number of children. Second, after substituting this number in the utility function, parents decide how much to invest in education taking into account the endogenous probability to emigrate. The optimal fertility rates of migrants and stayers are identical ${ }^{5}$ and amount to

$$
n_{t}^{*}=\frac{\beta(1-E)}{(1+\beta) \phi},
$$

Agents then maximize the expected utility function, given the endogenous probability to emigrate. The optimal investment in higher education is given by

$$
E_{t}^{*}=\frac{\sigma\left[1+p_{0} \log \left(w^{f}\right)\right]}{1+\beta+\sigma\left[1+p_{0} \log \left(A \bar{h}^{1-\sigma} w^{f}\right)\right]}
$$

To summarizer, parents' investments in higher education increase with the probability to emigrate $\left(\partial E_{t}^{*} / \partial p_{0}>0\right)$. Hence, given $(7)$, openness induces human capital and reduces fertility at origin since $\partial n_{t}^{*} / \partial E_{t}^{*}<0$. The mechanism is simple. As

\footnotetext{
${ }^{5}$ We could easily extend the model to account for the fact that fertility is lower in rich countries.
} 
argued in the new brain drain literature, migration prospects to richer countries stimulates human capital formation. This reduces the maximal amount of time that parents can devote to children education and labor. In empirical regressions, this first effect of migration on fertility can be easily accounted for by controlling for parents' human capital.

\subsection{Fertility, migration and children's education}

Let us now focus on the links between children's human capital and their probability to emigrate. In the second variant, we assume that parents have no possibility to invest in human capital: equation (2) is such that $E_{t}=0$ and $H_{t}=h_{t}$ is predetermined. They do not receive remittances. For simplicity, we assume that the probability that a child will emigrate is linearly increasing in human capital. The following specifications are used:

- Parents' probability to emigrate in (6) has a linear form: $\pi()=.H_{t}$.

- Parents' productivity in (2) is predetermined: $\Theta()=.h_{t}$.

- Children's human capital in (3) is endogenous: $\theta()=.e_{t}^{\gamma}$.

- Remittances are nil: $r_{t}=0$.

The optimization problem for remaining adults can thus be written as following:

$$
\left\{n_{t}, e_{t}\right\}=\arg \max \left\{\log \left[\left(1-\phi n_{t}\right) H_{t}-n_{t} e_{t}\right]+\beta \log \left[n_{t} e_{t}^{\gamma}\left(1+\omega p_{0} e_{t}^{\gamma}\right)\right]\right\}
$$

As shown in Appendix 7.2, an explicit analytical solution to this problem can be obtained for $\gamma=\frac{1}{2} .{ }^{6}$ The optimal fertility rate and investment in children education are characterized by the following system

$$
\begin{aligned}
n_{t}^{*} & =\frac{\beta H_{t}}{(1+\beta)\left(\phi H_{t}+e_{t}\right)} \\
e_{t}^{*} & =\left[\phi H_{t} \omega p_{0}+\sqrt{\left(\phi H_{t} \omega p_{0}\right)^{2}+\phi H_{t}}\right]^{2}
\end{aligned}
$$

First, for a given parental income, we have a negative relationship between fertility and investment in children's education. Clearly, in the absence of migration $\left(p_{0}=0\right)$, we have $e_{t}^{*}=\phi H_{t}$ and $n_{t}^{*}=\frac{\beta}{(1+\beta) 2 \phi}$. The fertility rate is independent on parental income. With migration prospects, the optimal investment in education increases in $p_{0}$. Hence, for a given wage rate, fertility decreases with migration. This result contracts with Chen (2006) who shows that when the probability to emigrate is

\footnotetext{
${ }^{6}$ Numerical experiments reveal that similar qualitative results would be obtained with $\gamma \neq \frac{1}{2}$.
} 
exogenous, it does not affect the optimal education of children and fertility. In our framework with endogenous probability of migration, it comes out that $p_{0}>0$ implies the optimal fertility rate decreases with parental income. In empirical regressions, this second effect of migration on fertility can be accounted in two ways. First, average rate of migration of the sending country, as a proxy for $p_{0}$, can be introduced as a direct determinant of the home country fertility. Second, it is desirable to control for parents' human capital, which might be measured by the residents' education level.

\subsection{Fertility and remittances}

Migration also impacts on fertility through remittances sent by previous generation of migrants and /or members of the community. Indeed, We can reasonably consider that the amount of remittances positively depends on the stock of contemporaneous compatriots living abroad. In the third variant, we assume that parents have no possibility to invest in human capital $\left(E_{t}=0\right.$ and $H_{t}$ is predetermined) and that children face an exogenous probability to emigrate. However, we now introduce non labor income, which can be here interpreted as the amount of remittances. The following specifications are used:

- Parents' probability to emigrate in (6) has a linear form: $\pi()=$.1 .

- Parents' productivity in (2) is predetermined: $\Theta()=.h_{t}$.

- Children's human capital in (3) is endogenous: $\theta()=.e_{t}^{\gamma}$.

- Remittances are positive and exogenous: $r_{t}>0$.

The optimization problem of remaining adults can thus be written as the following

$$
\left\{n_{t}, e_{t}\right\}=\arg \max \left\{\log \left(\left[\left(1-\phi n_{t}\right) H_{t}-n_{t} e_{t}+r_{t}\right]+\beta \log \left[n_{t} e_{t}^{\gamma}\left(1+\omega p_{0}\right)\right]\right\}\right.
$$

As shown in Appendix 7.3, the optimal fertility rate and investment in children's education are given by

$$
\begin{aligned}
n_{t}^{*} & =\frac{\beta(1-\gamma)\left(1+\frac{r_{t}}{H_{t}}\right)}{(1+\beta) \phi} \\
e_{t}^{*} & =\frac{\gamma \phi H_{t}}{1-\gamma}
\end{aligned}
$$

The optimal fertility rates increases with the amount of remittances (linked to the number of migrants abroad).

The latter result is closely linked to the choice of the utility function and the timing of remittances. Assume that the second component of the utility function (1) is not due to parental altruism but to the fact that parents care about old-age 
security. Assuming that working-aged children transfer a fraction $\tau$ of their income to their parents and parents also receive other transfers when old, the utility function would become:

$$
U_{t}=\log \left(c_{t}\right)+\beta \log \left(\tau \widetilde{w}_{t+1} h_{t+1} n_{t}+r_{t+1}^{o}\right)
$$

where $r_{t+1}^{o}$ includes remittances sent by extra-family members to old parents.

Adults' optimization problem can thus be written as the following

$$
\left\{n_{t}, e_{t}\right\}=\arg \max \left\{\log \left(\left[\left(1-\phi n_{t}\right) H_{t}-n_{t} e_{t}\right]+\beta \log \left[\tau n_{t} e_{t}^{\gamma}\left(1+\omega p_{0}\right)+r_{t+1}^{o}\right]\right\}\right.
$$

The optimal fertility rate and investment in children's education become

$$
\begin{aligned}
n_{t}^{*} & =\frac{\beta(1-\gamma)}{1+\beta}-\frac{r_{t+1}^{o}}{(1+\beta) \tau e_{t}^{\gamma}\left(1+\omega p_{0}\right)} \\
e_{t}^{*} & =\frac{\gamma \phi H_{t}}{1-\gamma}
\end{aligned}
$$

Under the old-age security hypothesis, the optimal fertility rates decreases with the expected amount of remittances received when old. In sum, the effect of extrafamily remittances is thus ambiguous. It can be positive of the income effect dominates or negative if the old-age security effect dominates.

\subsection{Transfers of norms}

As argued in Fargues (2007), one could also argue that migrants transfer fertility norms to those left behind. To model this hypothesis, let us consider the altruistic variant of our model and introduce alternative preferences regarding fertility. The novelty is that, in deciding on the number of children, parents internalize the gain of utility from conformity to the norm for fertility. Katav-Herz (2003) applied this idea to the choice of fertility, child education and child labor.

It is well documented that migrants abroad progressively assimilate in terms of fertility choices. In particular, the average fertility rate of first-generation immigrants from developing countries is lower than the fertility rate at origin, although higher than the average fertility rate of natives at destination. Just as migrants facilitate transfers of knowledge and ideas, they are also likely to transfer fertility norms to those left behind. We formalize this idea by introducing a reference level $\widetilde{n}_{t}$ of fertility (or norm) in the utility function and assume that adults derive utility from $n_{t}-\widetilde{n}_{t}$ (instead of obtaining utility from $n_{t}$, adults derive utility from having generally more children than the reference number of children).

In this variant, we consider that parents cannot invest in education $\left(H_{t}=h_{t}\right.$ is predetermined) and the probability of migration is exogenous (for parent and children). The following specifications are used:

- Parents' probability to emigrate in (6) has a linear form: $\pi()=$.1 . 
- Parents' productivity in (2) is predetermined: $\Theta()=.h_{t}$.

- Children's human capital in (3) is endogenous: $\theta()=.e_{t}^{\gamma}$.

- Remittances are nil: $r_{t}=0$.

Introducing the norm in the utility function (1), the optimization problem of non-migrant adults becomes

$$
\left\{n_{t}, e_{t}\right\}=\arg \max \left\{\log \left(\left[\left(1-\phi n_{t}\right) H_{t}-n_{t} e_{t}\right]+\beta \log \left[\left(n_{t}-\widetilde{n}_{t}\right) e_{t}^{\gamma}\left(1+\omega p_{0}\right)\right]\right\}\right.
$$

As shown in Appendix 7.4, the optimal fertility rate and investment in children's education are given by

$$
\begin{aligned}
n_{t}^{*} & =\frac{\phi \widetilde{n}_{t}+\beta(1-\gamma)+\sqrt{\left[\phi \widetilde{n}_{t}+\beta(1-\gamma)\right]^{2}+4 \beta \gamma \phi(1+\beta)}}{2 \phi(1+\beta)} \\
e_{t} & =\frac{\gamma \phi H_{t}\left(n_{t}-\widetilde{n}_{t}\right)}{n(1-\gamma)+\widetilde{n} \gamma}
\end{aligned}
$$

When $\widetilde{n}=0$, we have $n_{t}^{*}=\frac{\beta(1-\gamma)}{\phi(1+\beta)}$ as in the usual model. When $\widetilde{n}$ is positive, it is obvious that the optimal fertility is an increasing function of $\widetilde{n}$ (and is independent on parental income). Hence, if a transfer of norms reduces the reference level of fertility in the origin society, it impacts negatively on the optimal fertility rate.

The diffusion technology can be a complex function of the geographical distribution of the population and of fertility rate differentials across countries. We disregard here the link between the fertility norm and the lagged fertility rate of the domestic country to concentrate on the part of the norm affected by emigration. If $\theta_{d, t}$ is the proportion of the emigrant population living in country $d$, we can define by $\bar{n}^{d}=\sum_{d} \theta_{d} n_{d}$ the average fertility rate at destination $(d=1, \ldots, D$ are foreign destinations). Since $p_{0}$ denotes the average emigration rate, a reasonable diffusion technology can be written as

$$
\widetilde{n}=N\left(p_{0}, \bar{n}^{d}\right)
$$

with $N_{1}^{\prime} \geq 0$ and $N_{2}^{\prime} \geq 0$.

For example, if $N()=.\left(\bar{n}^{d}\right)^{\phi\left(p_{0}\right)}$, we have $\ln (\widetilde{n})=\phi\left(p_{0}\right) \cdot \ln \left(\bar{n}^{d}\right)$. If $\phi^{\prime}$ is low or nil, it means that the diffusion of norms is relatively independent of the intensity of migration, and emigrants-based norms can be seen. If $\phi^{\prime}$ is high, the diffusion of norms depends on the intensity of migration.

\section{Empirical analysis}

The model presented in section 3 enables us to identify the various channels through which migration can affect fertility in source countries. It also emphasizes the role of 
education for explaining the prevailing fertility behavior. The identified channels are embedded in the regression model specified below.

\subsection{Econometric specification}

Our dependent variable is the log of the fertility rate in source countries, $\log \left(n_{t}\right)$. The main explanatory variables of interest are the following.

- The "norms-diffusion" model predicts that the fertility rate should be increasing in the average fertility rate at destination. We assume a linear form for $\phi\left(p_{0}\right)$, i.e. $\phi\left(p_{0}\right)=a_{1}+a_{2} \cdot p_{0}$. From (18), the log of the norm has two additively separable terms and can be written as $\log (\widetilde{n})=a_{1} \log \left(\bar{n}^{d}\right)+a_{2} p_{0} \log \left(\bar{n}^{d}\right)$. We expect a non-negative sign for the estimates of $a_{1}$ and $a_{2}$ in the empirical equation (19) below. A similar technology is used by Spilimbergo (2008) who empirically showed that foreign-educated individuals promote democracy in their home country, but only if the foreign education is acquired in democratic countries. He constructs an index of average democracy in host countries, which is defined as the weighted average of democracy indices in host countries where a country's weight is the share of students going to that country over all foreign students from the origin country. Here, we transpose the same conceptual diffusion model to fertility behavior.

- By altruism, the fertility rate should be decreasing with a country's average emigration rate and with quality-selective immigration policies at destination. This suggests the use of two relevant explanatory variables. The first one is the average emigration rate $\left(p_{0}\right)$. It is measured by the total emigration rate. The second one aims at measuring selection in migration flows and is proxied by the ratio of migrants to residents for skilled relative to unskilled labor $(S)$. These variables are taken in logs and we expect a negative sign for the estimates of $a_{3}$ and $a_{4}$ in the empirical equation (19) below.

- Fertility is ambiguously affected by the amount of remittances sent by extrafamily compatriots abroad. The income effect predicts that the fertility rate should be increasing in remittances received when adult. However, the oldage security model predicts that fertility should be decreasing in remittances received before retirement since part can be saved for retirement. The expected sign for $a_{5}$ is therefore ambiguous. Controlling for remittances $R$ in empirical regressions will reveal the sign of the global impact of this variable.

- Theory predicts that migration prospects can stimulate the education of adults. Since educated parents have a higher opportunity cost of time, one expects the fertility rate to decrease in adults' human capital. In our regression, we will use the proportion of adults aged $25+$ with secondary and/or post-secondary education (denoted by $H$ ) and expect a negative sign for the estimate of $a_{6}$. 
- Finally, we also control for a set of $K$ explanatory variables $X_{k}(k=1, \ldots, K)$ which are not necessarily linked to international migration but potentially have an impact on fertility decision. We include the log of GDP per capita, the urbanization rate, regional dummies as well variables capturing the type and intensity of religious practice in source countries.

The benchmark empirical model can thus be written as:

$$
\begin{aligned}
\log (n)= & a_{0}+a_{1} \cdot \ln \left(\bar{n}^{d}\right)+a_{2} \cdot p_{0} \ln \left(\bar{n}^{d}\right)+a_{3} \cdot \ln \left(p_{0}\right) \\
& +a_{4} \cdot \ln (S)+a_{5} \cdot \ln (R)+a_{6} \cdot H+\sum_{k} b_{k} \cdot X_{k}+\varepsilon
\end{aligned}
$$

where $a_{0}$ is a constant and $\varepsilon_{t}$ is a iid error term.

Our main coefficient of interest are $a_{1}$ which determines the significance and magnitude of the diffusion of fertility norms. The expected theoretical sign of $a_{1}$ is positive. We also interact the (log of) fertility rate at destination with the size of the diaspora to assess the robustness of the impact to the intensity of migration. In this set up, the emigration rate is also associated to the incentive channel $\left(a_{4}\right)$. We assume that the incentive effect follows a concave pattern and is measured by $\ln \left(p_{0}\right)$. The expected theoretical sign of $a_{4}$ is negative, as higher migration prospects increase the incentive to invest in education and reduce fertility at home.

\subsection{Data}

Our regression involve cross section data because the migration stocks used to build fertility at destination $\bar{n}^{d}$ are only available for 2000. Data on fertility rates $\left(n_{t}\right)$ are taken from the World Development Indicators. The fertility rate is the average number of children that women have during their lives, from age 15 to age 50 . To compute data on average emigration rates $\left(p_{0}\right)$ and geographic shares of the emigrant population by destination $\left(\theta_{d, t}\right)$, we use the data set developed by Parsons, Skeldon, Walmsley and Winters (2007). They provide four versions of an international bilateral migration stock database for 208 countries and territories of origin and destination for the year 2000. We use the fourth comprehensive version which uses a variety of techniques to estimate the missing data. The final matrix, comprising only the foreign-born reconcile all of the available information in order to provide the researcher with a single and complete matrix of international bilateral migrant stocks.

One striking picture coming out of the data is the importance of South-South migration (to non OECD countries). Not surprisingly, North-South migration is negligible as all OECD countries send most of their migrants to other OECD countries. To illustrate the importance South-South migration, it turns out that 47 percent of developing countries have their main destination in a non-OECD countries. Out of those countries, 81 percent send their migrants mostly to a neighboring country. 
This is line with the well known stylized fact of prevailing liquidity constraints in international migration (Lopez and Schiff, 1998; Mayda, 2006).

The intensity of South-South migration is important for our analysis for two reasons. First, it suggests that migrants are by no means concentrated in OECD countries. Therefore, the fertility norms that they will transmit from abroad are much more heterogeneous that one would expect if most migrants were located in OECD countries. Second, it suggests that the impact of fertility norms might work in both directions. In fact, 83 countries have an average fertility at destination that is higher than the one prevailing at home (i.e. 40 percent of the full sample of 208 countries). If we consider only developing countries, this situation if observed in 44 cases (i.e. 28 percent of the sample of 155 developing countries)

Combining the fertility data with the bilateral migration matrix allows us to compute weighted average fertility rate at destination, as in equation(18). As expected from the observed patterns of migration and the importance of South-South migration as well as the range of fertility rates, the average fertility rates at destination $\bar{n}^{d}$ exhibit a high degree of variability, ranging from 1.40 to 5.58 .

Table 1 describes the distribution of the fertility rates by country groups. The countries are classified along different criteria : income (high income vs developing countries), data availability regarding important variables such as the remittances, geographical location and religion. In 2000, the fertility rates vary significantly across location of the country, from 4.8 children per woman in Africa to 1.4 in Europe. At the world level, the fertility rate is equal to 3.2 children per woman on average and ranges from 0.9 in Macau to 7.95 in Niger. Table 1 also provides fertility rates at destination, i.e. values for $\bar{n}^{d}$. The fertility rates at destination are significantly higher for Sub Saharan countries and to a lesser extent Islamic countries. This might be explained by their emigration patterns. In Sub-Saharan Africa, a large share of the migration flows is towards neighboring countries that also display high fertility levels. In Islamic countries such as Egypt of Pakistan, a lot of workers migrate to Gulf countries in which the fertility rates are relatively high. 


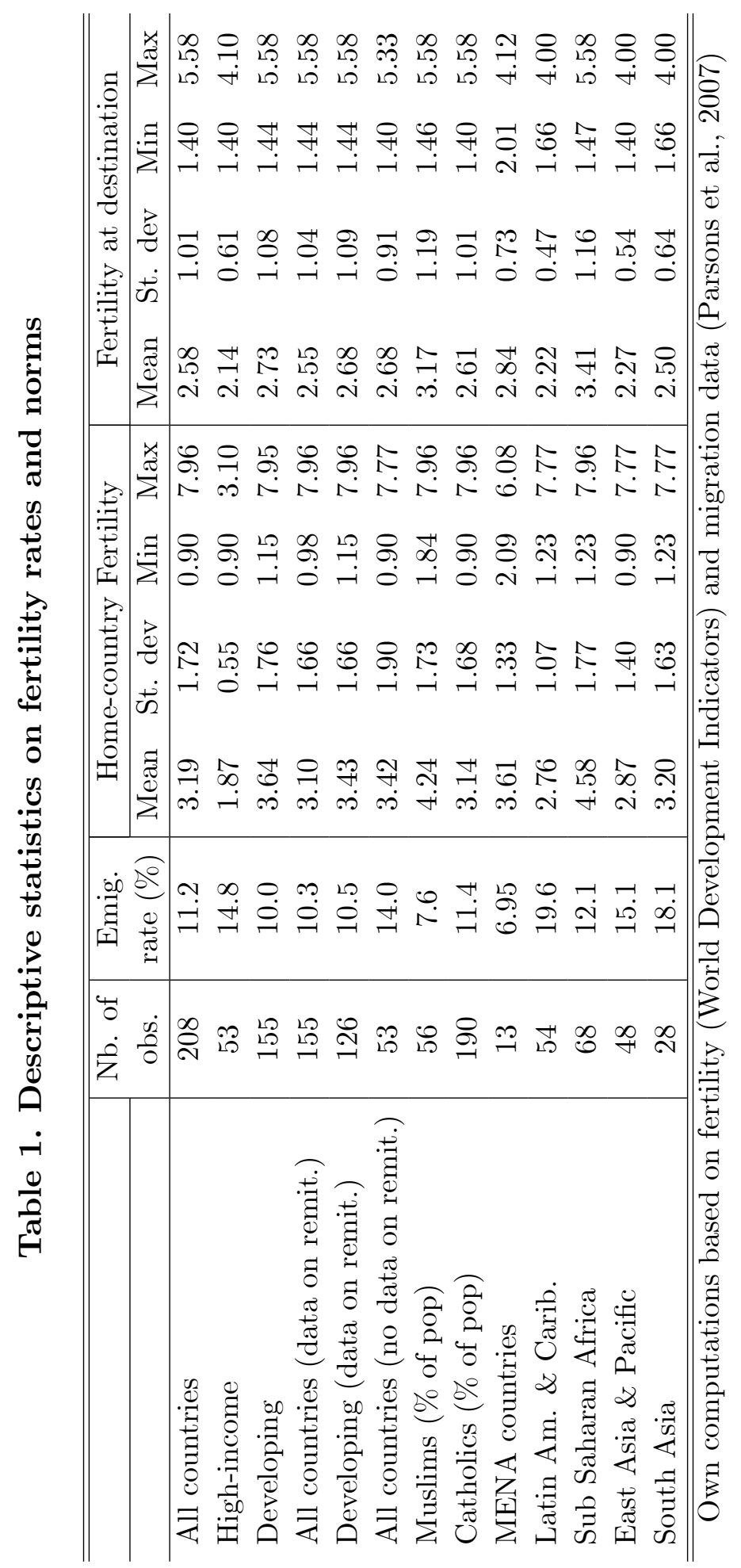


Data on human capital $\left(H_{t}\right)$ on positive selection in emigration $\left(S_{t}\right)$, proxied by the skilled-to-unskilled ratio of emigration rates to rich countries, are computed by Docquier et al. (2007). Emigration rates $\left(p_{0}\right)$ are also computed from the Parsons et al. (2007) database. Data on remittances are taken from the IMF database. In our set of controls, we include the urbanization rate (available in the World Development Indicators $)^{7}$, regional and religious dummies. Regional dummies are consistent with the World Bank definition. Given the low number of countries (8) in South Asia, we join those countries with the Europe and Central Asia (ECA) region. Religion variables are measured in two ways. We first capture those by the proportion of Catholics and Muslims in the country. Alternatively, we introduce a dummy for countries belonging to the organization of the Islamic Conference.

\subsection{Results}

Tables 2, 3 and 4 report the results for the benchmark regressions. These are obtained using OLS (in Table 2) and IV (in Table 3) estimations accounting for potential endogeneity problems. Each table reports the estimation results from a set of variants in terms of specifications and the used variables.

OLS regressions. Let us start with OLS regressions in Table 2 using the benchmark specification (19). In this set up, the norm is supposed to be given by $\ln \left(\widetilde{n}_{t}\right)=\ln \left(\bar{n}^{d}\right)+p_{0} \ln \left(\bar{n}^{d}\right)$. Following Spilimbergo (2008), the interaction term $p_{0} \ln \left(\bar{n}^{d}\right)$ tests whether the impact of fertility at destination (the fertility norm) depends on the intensity of migration or not.

The data constraints tend to influence significantly the sample size. If we use the full set of explanatory variables, data unavailability for a couple variables such as remittances, GDP per head, share of Catholics in the countries and the selection ratio reduces the sample size. The most important reduction comes from the use of remittances, which are unavailable for 53 countries. Therefore, we estimate the model with and without remittances as an explanatory variable. The estimation results without (resp. with) are presented in columns (1) and (2) (resp. columns (3) and (4)). The use of the other variables leads to a further reduction of the usable sample, with 175 countries in the largest sample and 145 countries when remittances are included. In all Tables, we estimate for each sample a full specification (columns 1 and 3) as well as a parsimonious one (columns 1 and 4) to increase efficiency in the estimation.

\footnotetext{
${ }^{7}$ Sato (2007) and Sato and Yamamoto (2005) discuss the effect of agglomeration and urbanization on fertility rates.
} 
Table 2. OLS regressions (dep = log of fertility rate) - All countries

\begin{tabular}{|c|c|c|c|c|}
\hline & (1) & $(2)$ & (3) & (4) \\
\hline Constant & $\begin{array}{c}1.200 \\
(5.51)^{* * *}\end{array}$ & $\begin{array}{c}1.037 \\
(6.23)^{* * *}\end{array}$ & $\begin{array}{c}1.459 \\
(5.11)^{* * *}\end{array}$ & $\begin{array}{c}1.432 \\
(5.92)^{* * *}\end{array}$ \\
\hline Log of fertility at dest & $\begin{array}{c}0.343 \\
(3.35)^{* * *}\end{array}$ & $\begin{array}{c}0.383 \\
(4.37)^{* * *}\end{array}$ & $\begin{array}{c}0.273 \\
(2.40)^{* *}\end{array}$ & $\begin{array}{c}0.291 \\
(2.76)^{* * *}\end{array}$ \\
\hline$p_{0} . \log$ of fertility at dest & $\begin{array}{r}-0.202 \\
(0.77)\end{array}$ & & $\begin{array}{c}-0.405 \\
(1.54)\end{array}$ & \\
\hline $\log$ of $p_{0}$ & $\begin{array}{l}-0.025 \\
(0.78)\end{array}$ & $\begin{array}{l}-0.040 \\
(1.90)^{*}\end{array}$ & $\begin{array}{r}-0.018 \\
(0.59)\end{array}$ & $\begin{array}{c}-0.053 \\
(2.44)^{* *}\end{array}$ \\
\hline Selection ratio (sec+tert) & $\begin{array}{l}0.001 \\
(0.04)\end{array}$ & & $\begin{array}{l}0.001 \\
(0.02)\end{array}$ & \\
\hline Log of remittances & & & $\begin{array}{l}0.018 \\
(1.16)\end{array}$ & $\begin{array}{c}0.032 \\
(2.18)^{* *}\end{array}$ \\
\hline Urbanization & $\begin{array}{c}-0.005 \\
(2.62)^{* * *}\end{array}$ & $\begin{array}{c}-0.005 \\
(2.88)^{* * *}\end{array}$ & $\begin{array}{c}-0.004 \\
(2.54)^{* *}\end{array}$ & $\begin{array}{c}-0.003 \\
(2.24)^{* *}\end{array}$ \\
\hline GDP per capita & $\begin{array}{c}-0.076 \\
(2.46)^{* *}\end{array}$ & $\begin{array}{c}-0.079 \\
(3.32)^{* * *}\end{array}$ & $\begin{array}{c}-0.100 \\
(2.80)^{* * *}\end{array}$ & $\begin{array}{c}-0.117 \\
(3.86) * * *\end{array}$ \\
\hline Adult's education & $\begin{array}{l}-0.256 \\
(1.70)^{*}\end{array}$ & & $\begin{array}{r}-0.190 \\
(1.09)\end{array}$ & \\
\hline East Asia \& Pacific & $\begin{array}{c}0.272 \\
(2.85)^{* * *}\end{array}$ & $\begin{array}{c}0.277 \\
(2.99)^{* * *}\end{array}$ & $\begin{array}{c}0.308 \\
(3.29)^{* * *}\end{array}$ & $\begin{array}{c}0.272 \\
(2.90)^{* * *}\end{array}$ \\
\hline Sub-Saharan Africa & $\begin{array}{c}0.427 \\
(4.67)^{* * *}\end{array}$ & $\begin{array}{c}0.420 \\
(4.72)^{* * *}\end{array}$ & $\begin{array}{c}0.537 \\
(4.75)^{* * *}\end{array}$ & $\begin{array}{c}0.521 \\
(5.40)^{* * *}\end{array}$ \\
\hline Latin Am. \& Carib & $\begin{array}{c}0.350 \\
(5.13)^{* * *}\end{array}$ & $\begin{array}{c}0.323 \\
(5.31)^{* * *}\end{array}$ & $\begin{array}{c}0.451 \\
(6.49)^{* * *}\end{array}$ & $\begin{array}{c}0.486 \\
(8.03)^{* * *}\end{array}$ \\
\hline Mena & $\begin{array}{l}0.115 \\
(1.21)\end{array}$ & & $\begin{array}{l}0.159 \\
(1.26)\end{array}$ & \\
\hline High-income & $\begin{array}{l}0.089 \\
(0.96)\end{array}$ & & $\begin{array}{c}0.229 \\
(2.22)^{* *}\end{array}$ & $\begin{array}{c}0.239 \\
(2.70)^{* * *}\end{array}$ \\
\hline Muslims (\% of pop) & $\begin{array}{c}0.004 \\
(4.40)^{* * *}\end{array}$ & $\begin{array}{c}0.004 \\
(5.59)^{* * *}\end{array}$ & $\begin{array}{c}0.003 \\
(2.96)^{* * *}\end{array}$ & $\begin{array}{c}0.003 \\
(4.55)^{* * *}\end{array}$ \\
\hline Catholic (\% of pop) & $\begin{array}{c}0.001 \\
(1.81)^{*}\end{array}$ & $\begin{array}{c}0.002 \\
(2.68)^{* * *}\end{array}$ & $\begin{array}{c}0.001 \\
(1.43)\end{array}$ & \\
\hline Observations & 175 & 175 & 145 & 145 \\
\hline R-squared & 0.78 & 0.77 & 0.83 & 0.81 \\
\hline
\end{tabular}

Robust t statistics in parentheses

* significant at $10 \% ; * *$ significant at $5 \%$; *** significant at $1 \%$ 
Table 2 reports the estimates of model (19) for the sample of all countries. Let us first focus on parameters of interest. First, all estimations point to a positive and significant impact of fertility norms. For the two samples (with and without remittances), we find a significant $a_{1}$ coefficient. The elasticity ranges between 0.27 and 0.34 . In contrast, in all regressions, the interaction term $p_{0} \ln \left(\bar{n}^{d}\right)$ turns out to be insignificant, suggesting that the transfer of norm does not depend on the intensity of migration. In subsequent regressions, this interaction term is dropped in order to increase efficiency in the parameter. Our estimates therefore suggest that on average, a decrease of $1 \%$ of the fertility at destination leads to a decrease of about $0.30 \%$ in the home country fertility.

The estimation results also point to a (weakly) significant incentive impact, as reflected by the negative and significant parameter $a_{3}$, as reflected by the results of the parsimonious regressions (columns 2 and 4 ). The results support the idea that higher migration prospects tend to slightly reduce fertility at home, possibly through a higher investment in education. The coefficient associated to the selection ratio $\left(a_{4}\right)$ is however non significant and is also dropped in the subsequent parsimonious regressions. The negative estimate of the adults' education level $\left(a_{6}\right)$ is in line with the incentive impact of migration through investment in education. The weakly significant coefficient might be explained by the high collinearity with the level of GDP per head, especially given the cross sectional dimension data. ${ }^{8}$ It is therefore dropped in parsimonious specifications. As for the impact of remittances $\left(a_{5}\right)$, we find moderate support for a positive impact on fertility at home in the parsimonious specification. This could suggest that the income effect slightly dominates the negative impact associated to the old-age security. Nevertheless, one might expect that old-age security effect of the migrant's transfers play a higher role in developing countries than in developed countries. We check this point below when restricting the sample to developing countries only.

As for the control variables included in regression (19), our results are mostly in line with the expected impact. Fertility rates are found to decrease with income per capita. They are found to be higher in Islamic countries and increase with the proportion of Catholics in the country. Compared to the ECA-SA region, fertility rates are higher Sub Saharan Africa, Latin America and East Asia and Pacific.

IV regressions. The OLS estimation of model (19) rests on the assumption that all covariates are independent of $\varepsilon_{t}$. Nevertheless, it might be argued that some variables might depend on fertility, invalidating this assumption. In particular, higher fertility rates should increase labor supply and depress wages in domestic countries, affecting international migration. In other words, $\ln \left(p_{0}\right)$ that captures the incentive channel might depend on the level of the home country fertility rate $\ln \left(n_{t}\right)$. In this case, reverse causality might affect directly the quality of the estimation of $a_{3}$ but also

${ }^{8}$ The correlation between the adults' human capital and incoime per head amounts to 0.67 (resp. 0.57 ) for the full sample (resp. sample of developing countries). 
the ones of other coefficients such as $a_{1}{ }^{9}$. If such an effect is quantitatively important, it might be desirable to carry out instrumental variable estimation. Note that since we are using migration shares across destination countries $\left(\theta_{d}\right)$ rather than stocks of migrants to build the norm variable, we can rule out any reverse causality running from $\ln \left(n_{t}\right)$ to $\ln \left(\bar{n}_{t}^{d}\right)$.

Table 3 reports the IV estimates of model (19) for the whole sample of countries. We consider the following instruments of the (log of) emigration rate: a dummy variable for islands, the (log of the) size of the country measured by its surface (in squared kilometers) and (the log of the) distance to main destination of the migrants. ${ }^{10}$ It is worth emphasizing that the two necessary conditions for instrumentation are fulfilled in our regressions. First, the first stage estimation results indicate that we have strong instruments. The $F$ statistics of the first stage regressions are most of the time above 10. The partial correlations of the first stage regression show that the 3 instruments explain a significant part of the variability of emigration rates. Second, as suggested by the $p$-value of the Hansen overidentification test, those instruments are found to be independent of the fertility rates. The test fails to reject the null hypothesis of independence between the instrument set and the error term.

The main findings of the IV estimations are broadly similar to those of the OLS estimations. We find evidence of a shifting norm effect $\left(a_{1}\right)$ and reject the existence of an interaction effect with the emigration intensity $\left(a_{2}\right)$. The elasticity of the transfer of norm also remains quite in line with the one estimated by the OLS regressions. It is however slightly lower for the sample of countries for which data of remittances are available. We find moderate evidence of an incentive effect of migration on fertility, as suggested by the estimate of $a_{3}$ in the parsimonious specification including the remittances. In this set up, the slightly positive impact of remittances on fertility rates is also confirmed. On the whole, the impact of the other variables are in general in line with the one found in OLS regressions.

\footnotetext{
${ }^{9}$ Theoretically speaking, the existence of a reverse causality between migration and fertility implies that the interaction term (emigration rate times the fertility norm) should also be instrumented. Nevertheless, since this term is insignificant in OLS regressions, we focus on the instrumentation of the emigration rate only.

${ }^{10}$ The first stage regressions of the IV estimations yield estimates that are in line with intuition. In particular, size is negatively associated to emigration rates. Islands are found to display higher migration rates and higher distance to main destination negatively affects emigration rates. The estimation results are not reported here to save space but can be obtained upon request to the first author.
} 
Table 3. IV regressions (dep = log of fertility rate) - All countries

\begin{tabular}{|c|c|c|c|c|}
\hline & $(1)$ & $(2)$ & $(3)$ & $(4)$ \\
\hline Constant & $\begin{array}{c}1.253 \\
(5.99)^{* * *}\end{array}$ & $\begin{array}{c}1.116 \\
(5.90)^{* * *}\end{array}$ & $\begin{array}{c}1.482 \\
(6.30)^{* * *}\end{array}$ & $\begin{array}{c}1.101 \\
(5.86)^{* * *}\end{array}$ \\
\hline Log of fertility at dest & $\begin{array}{c}0.385 \\
(3.44)^{* * *}\end{array}$ & $\begin{array}{c}0.390 \\
(4.18)^{* * *}\end{array}$ & $\begin{array}{c}0.236 \\
(1.91)^{*}\end{array}$ & $\begin{array}{c}0.273 \\
(2.57)^{* *}\end{array}$ \\
\hline$p_{0} . \log$ of fertility at dest & $\begin{array}{r}-0.223 \\
(0.41)\end{array}$ & & $\begin{array}{l}-0.090 \\
(0.23)\end{array}$ & \\
\hline $\log$ of $p_{0}$ & $\begin{array}{r}-0.020 \\
(0.28)\end{array}$ & $\begin{array}{l}-0.019 \\
(0.52)\end{array}$ & $\begin{array}{l}-0.060 \\
(1.12)\end{array}$ & $\begin{array}{c}-0.075 \\
(2.45)^{* *}\end{array}$ \\
\hline Selection ratio (sec+tert) & $\begin{array}{r}-0.005 \\
(0.18)\end{array}$ & & $\begin{array}{l}-0.017 \\
(0.58)\end{array}$ & \\
\hline Log of remittances & & & $\begin{array}{l}0.019 \\
(1.29)\end{array}$ & $\begin{array}{c}0.032 \\
(2.17)^{* *}\end{array}$ \\
\hline Urbanization & $\begin{array}{c}-0.005 \\
(2.79)^{* * *}\end{array}$ & $\begin{array}{c}-0.005 \\
(2.69)^{* * *}\end{array}$ & $\begin{array}{c}-0.005 \\
(2.97)^{* * *}\end{array}$ & $\begin{array}{c}-0.005 \\
(2.88) * * *\end{array}$ \\
\hline GDP per capita & $\begin{array}{c}-0.075 \\
(2.17)^{* *}\end{array}$ & $\begin{array}{c}-0.072 \\
(2.81)^{* * *}\end{array}$ & $\begin{array}{c}-0.107 \\
(3.18) * * *\end{array}$ & $\begin{array}{c}-0.063 \\
(2.74)^{* * *}\end{array}$ \\
\hline Adult's education & $\begin{array}{l}-0.282 \\
(1.87)^{*}\end{array}$ & & $\begin{array}{l}-0.204 \\
(1.24)\end{array}$ & \\
\hline East Asia \& Pacific & $\begin{array}{c}0.238 \\
(2.51)^{* *}\end{array}$ & $\begin{array}{c}0.245 \\
(2.63)^{* * *}\end{array}$ & $\begin{array}{c}0.268 \\
(2.70)^{* * *}\end{array}$ & $\begin{array}{c}0.220 \\
(2.38)^{* *}\end{array}$ \\
\hline Sub-Saharan Africa & $\begin{array}{c}0.372 \\
(4.35)^{* * *}\end{array}$ & $\begin{array}{c}0.434 \\
(5.15)^{* * *}\end{array}$ & $\begin{array}{c}0.499 \\
(4.69)^{* * *}\end{array}$ & $\begin{array}{c}0.495 \\
(5.22)^{* * *}\end{array}$ \\
\hline Latin Am. \& Carib & $\begin{array}{c}0.321 \\
(4.57)^{* * *}\end{array}$ & $\begin{array}{c}0.371 \\
(6.27)^{* * *}\end{array}$ & $\begin{array}{c}0.435 \\
(5.92)^{* * *}\end{array}$ & $\begin{array}{c}0.412 \\
(7.18)^{* * *}\end{array}$ \\
\hline Mena & $\begin{array}{l}0.076 \\
(0.73)\end{array}$ & & $\begin{array}{c}0.238 \\
(2.39)^{* *}\end{array}$ & \\
\hline High-income & $\begin{array}{c}0.169 \\
(1.81)^{*}\end{array}$ & $\begin{array}{c}0.191 \\
(2.26)^{* *}\end{array}$ & $\begin{array}{c}0.205 \\
(1.98)^{* *}\end{array}$ & $\begin{array}{l}0.134 \\
(1.62)\end{array}$ \\
\hline Muslims (\% of pop) & $\begin{array}{c}0.235 \\
(4.17)^{* * *}\end{array}$ & $\begin{array}{c}0.220 \\
(4.02)^{* * *}\end{array}$ & $\begin{array}{c}0.227 \\
(3.88) * * *\end{array}$ & $\begin{array}{c}0.210 \\
(3.68)^{* * *}\end{array}$ \\
\hline Catholic (\% of pop) & $\begin{array}{r}0.001 \\
(1.17) \\
\end{array}$ & & $\begin{array}{l}0.001 \\
(1.21) \\
\end{array}$ & \\
\hline Partial Corr First Stage & 0.174 & 0.342 & 0.212 & 0.400 \\
\hline F-stat First Stage & 12.39 & 20.27 & 11.26 & 36.36 \\
\hline Hansen J Test (p-value) & 0.130 & 0.319 & 0.63 & 0.67 \\
\hline R-squared & 0.774 & 0.757 & 0.824 & 0.803 \\
\hline Observations & 174 & 175 & 144 & 144 \\
\hline
\end{tabular}

Robust t statistics in parentheses

Instruments for $\ln (\mathrm{p} 0)$ : island, $\ln ($ size $), \ln ($ distance to main destination)

* significant at $10 \% ;{ }^{* *}$ significant at $5 \% ;{ }^{* * *}$ significant at $1 \%$ 
Focusing on developing countries. The results of the benchmark regressions tend to support the existence of a transfer of norms between countries in terms of fertility. In this section, we assess the sensitivity of the choice of the included countries in the sample. Here, we restrict our attention to the determinants of fertility rates in the developing countries only. This robustness check stems at least for two reasons. First, although we have no direct evidence for that, it might be expected that norms might in the first instance be from developed to developing countries. Second, other channels through which migration affect fertility might differ between developed and developing countries. One obvious example concerns the impact of remittances. One might expect that the effect of transfers associated to old-age security concerns is stronger in developing countries in which legal pension systems are much less developed. In this case, we should expect the impact of remittances on fertility rates to be less positive or even to be negative as the income effect will be more offset by the old-age security effect.

Table 4 and Table 5 report the results with the sample of developing countries only. A country is considered developed if it is classified as a high income country in the World Bank classification. The results might summarized as follows. We find confirmation of strongly significant effect of a transfer of norms in all regressions. Nevertheless, we do not find any significant difference in the elasticity between the full sample and the one including the developing countries only. We also find confirmation that this impact does not depend directly on the intensity of migration, as the influence of the interaction term $p_{0} \ln \left(\bar{n}^{d}\right)$ is always strongly rejected in all regressions. We find moderate evidence of an incentive effect of migration through investment in education (see Table 5 and in particular IV estimate of $a_{3}$ in a parsimonious specification with the remittances included as a control variable). Interestingly, we find less positive impact of remittances on the fertility rates for developing countries, although our regressions clearly rejects the hypothesis that old-age security effect dominates the income one. 
Table 4. OLS regressions (dep = log of fertility rate) Developing countries

\begin{tabular}{|c|c|c|c|c|}
\hline & $(1)$ & $(2)$ & $(3)$ & $(4)$ \\
\hline \multirow[t]{2}{*}{ Constant } & 1.270 & 1.267 & 1.587 & 1.525 \\
\hline & $(5.40)^{* * *}$ & $(6.20)^{* * *}$ & $(5.17)^{* * *}$ & $(6.29)^{* * *}$ \\
\hline \multirow[t]{2}{*}{ Log of fertility at dest } & 0.337 & 0.338 & 0.267 & 0.261 \\
\hline & $(3.28)^{* * *}$ & $(3.65)^{* * *}$ & $(2.26)^{* *}$ & $(2.34)^{* *}$ \\
\hline \multirow[t]{2}{*}{$p_{0} \cdot \log$ of fertility at dest } & -0.181 & & -0.368 & \\
\hline & $(0.60)$ & & $(1.21)$ & \\
\hline \multirow[t]{2}{*}{$\log$ of $p_{0}$} & -0.019 & -0.028 & -0.009 & -0.034 \\
\hline & $(0.54)$ & $(1.17)$ & $(0.28)$ & $(1.49)$ \\
\hline \multirow[t]{2}{*}{ Selection ratio (sec+tert) } & -0.001 & & -0.013 & \\
\hline & $(0.02)$ & & $(0.41)$ & \\
\hline \multirow[t]{2}{*}{ Log of remittances } & & & 0.008 & 0.016 \\
\hline & & & $(0.52)$ & $(1.14)$ \\
\hline \multirow[t]{2}{*}{ Urbanization } & -0.004 & -0.003 & -0.005 & -0.004 \\
\hline & $(1.97)^{*}$ & $(1.84)^{*}$ & $(2.87)^{* * *}$ & $(2.38)^{* *}$ \\
\hline \multirow[t]{2}{*}{ GDP per capita } & -0.088 & -0.094 & -0.112 & -0.116 \\
\hline & $(2.67)^{* * *}$ & $(3.25)^{* * *}$ & $(2.85)^{* * *}$ & $(3.81)^{* * *}$ \\
\hline \multirow[t]{2}{*}{ Adult's education } & -0.375 & -0.422 & -0.350 & -0.383 \\
\hline & $(2.30)^{* *}$ & $(2.67)^{* * *}$ & $(1.91)^{*}$ & $(2.15)^{* *}$ \\
\hline \multirow[t]{2}{*}{ East Asia \& Pacific } & 0.406 & 0.387 & 0.407 & 0.363 \\
\hline & $(3.50)^{* * *}$ & $(3.40)^{* * *}$ & $(3.98)^{* * *}$ & $(3.66) * * *$ \\
\hline \multirow[t]{2}{*}{ Sub-Saharan Africa } & 0.428 & 0.387 & 0.519 & 0.439 \\
\hline & $(4.55)^{* * *}$ & $(4.34)^{* * *}$ & $(4.52)^{* * *}$ & $(4.40)^{* * *}$ \\
\hline \multirow[t]{2}{*}{ Latin Am. \& Carib } & 0.335 & 0.298 & 0.414 & 0.344 \\
\hline & $(4.81)^{* * *}$ & $(4.38)^{* * *}$ & $(6.15)^{* * *}$ & $(5.23)^{* * *}$ \\
\hline \multirow[t]{2}{*}{ Mena } & 0.115 & & 0.192 & \\
\hline & $(1.11)$ & & $(1.40)$ & \\
\hline \multirow[t]{2}{*}{ Muslims (\% of pop) } & 0.004 & 0.005 & 0.004 & 0.004 \\
\hline & $(4.51)^{* * *}$ & $(5.44)^{* * *}$ & $(3.11)^{* * *}$ & $(4.93)^{* * *}$ \\
\hline \multirow[t]{2}{*}{ Catholic (\% of pop) } & 0.002 & 0.002 & 0.002 & 0.003 \\
\hline & $(2.62)^{* * *}$ & $(2.86)^{* * *}$ & $(3.03)^{* * *}$ & $(3.30)^{* * *}$ \\
\hline Observations & 143 & 143 & 119 & 119 \\
\hline R-squared & 0.77 & 0.76 & 0.84 & 0.83 \\
\hline
\end{tabular}

Robust t statistics in parentheses

* significant at $10 \%$; ** significant at $5 \%$; *** significant at $1 \%$ 
Table 5. IV regressions $(\mathrm{dep}=\log$ of fertility rate) Developing countries

\begin{tabular}{|c|c|c|c|c|}
\hline & (1) & $(2)$ & $(3)$ & $(4)$ \\
\hline Constant & $\begin{array}{c}1.319 \\
(5.35)^{* * *}\end{array}$ & $\begin{array}{c}1.388 \\
(6.02)^{* * *}\end{array}$ & $\begin{array}{c}1.529 \\
(5.62)^{* * *}\end{array}$ & $\begin{array}{c}1.422 \\
(6.42)^{* * *}\end{array}$ \\
\hline Log of fertility at dest & $\begin{array}{c}0.375 \\
(3.45)^{* * *}\end{array}$ & $\begin{array}{c}0.360 \\
(3.70)^{* * *}\end{array}$ & $\begin{array}{c}0.219 \\
(1.91)^{*}\end{array}$ & $\begin{array}{c}0.229 \\
(2.12)^{* *}\end{array}$ \\
\hline$p_{0} \cdot \log$ of fertility at dest & $\begin{array}{c}-0.695 \\
(1.14)\end{array}$ & & $\begin{array}{l}0.041 \\
(0.10)\end{array}$ & \\
\hline $\log$ of $p_{0}$ & $\begin{array}{l}0.048 \\
(0.62)\end{array}$ & $\begin{array}{l}0.005 \\
(0.12)\end{array}$ & $\begin{array}{l}-0.070 \\
(1.24)\end{array}$ & $\begin{array}{c}-0.069 \\
(2.22)^{* *}\end{array}$ \\
\hline Selection ratio (sec+tert) & $\begin{array}{l}0.016 \\
(0.44)\end{array}$ & & $\begin{array}{c}-0.024 \\
(0.71)\end{array}$ & \\
\hline Log of remittances & & & $\begin{array}{l}0.015 \\
(1.07)\end{array}$ & $\begin{array}{c}0.024 \\
(1.67)^{*}\end{array}$ \\
\hline Urbanization & $\begin{array}{c}-0.004 \\
(2.06)^{* *}\end{array}$ & $\begin{array}{l}-0.003 \\
(1.41)\end{array}$ & $\begin{array}{c}-0.005 \\
(2.95)^{* * *}\end{array}$ & $\begin{array}{c}-0.004 \\
(2.62)^{* * *}\end{array}$ \\
\hline GDP per capita & $\begin{array}{c}-0.070 \\
(1.81)^{*}\end{array}$ & $\begin{array}{c}-0.099 \\
(3.29)^{* * *}\end{array}$ & $\begin{array}{c}-0.118 \\
(3.28)^{* * *}\end{array}$ & $\begin{array}{c}-0.107 \\
(3.69)^{* * *}\end{array}$ \\
\hline Adult's education & $\begin{array}{c}-0.413 \\
(2.55)^{* *}\end{array}$ & $\begin{array}{c}-0.482 \\
(3.01)^{* * *}\end{array}$ & $\begin{array}{l}-0.318 \\
(1.83)^{*}\end{array}$ & $\begin{array}{l}-0.321 \\
(1.82)^{*}\end{array}$ \\
\hline East Asia \& Pacific & $\begin{array}{c}0.425 \\
(3.93)^{* * *}\end{array}$ & $\begin{array}{c}0.396 \\
(3.72)^{* * *}\end{array}$ & $\begin{array}{c}0.364 \\
(3.33)^{* * *}\end{array}$ & $\begin{array}{c}0.334 \\
(3.26)^{* * *}\end{array}$ \\
\hline Sub-Saharan Africa & $\begin{array}{c}0.445 \\
(4.43)^{* * *}\end{array}$ & $\begin{array}{c}0.378 \\
(4.08)^{* * *}\end{array}$ & $\begin{array}{c}0.502 \\
(4.99)^{* * *}\end{array}$ & $\begin{array}{c}0.451 \\
(4.97)^{* * *}\end{array}$ \\
\hline Latin Am. \& Carib & $\begin{array}{c}0.353 \\
(4.78)^{* * *}\end{array}$ & $\begin{array}{c}0.276 \\
(3.96)^{* * *}\end{array}$ & $\begin{array}{c}0.390 \\
(5.62)^{* * *}\end{array}$ & $\begin{array}{c}0.361 \\
(5.62)^{* * *}\end{array}$ \\
\hline Mena & $\begin{array}{c}0.098 \\
(0.88)\end{array}$ & & $\begin{array}{l}0.179 \\
(1.47)\end{array}$ & \\
\hline Muslims (\% of pop) & $\begin{array}{c}0.004 \\
(4.31)^{* * *}\end{array}$ & $\begin{array}{c}0.004 \\
(5.20)^{* * *}\end{array}$ & $\begin{array}{c}0.004 \\
(3.51)^{* * *}\end{array}$ & $\begin{array}{c}0.004 \\
(5.61)^{* * *}\end{array}$ \\
\hline Catholic (\% of pop) & $\begin{array}{c}0.002 \\
(2.22)^{* *}\end{array}$ & $\begin{array}{c}0.002 \\
(2.87)^{* * *}\end{array}$ & $\begin{array}{c}0.003 \\
(3.38)^{* * *}\end{array}$ & $\begin{array}{c}0.003 \\
(3.35)^{* * *}\end{array}$ \\
\hline Partial Corr First Stage & 0.150 & 0.336 & 0.183 & 0.367 \\
\hline F-stat First Stage & 9.46 & 19.00 & 8.03 & 25.40 \\
\hline Hansen J Test (p-value) & 0.298 & 0.420 & 0.803 & 0.623 \\
\hline R-squared & 0.755 & 0.758 & 0.829 & 0.824 \\
\hline Observations & 142 & 142 & 118 & 118 \\
\hline
\end{tabular}

Robust t statistics in parentheses.

Instruments for $\ln (\mathrm{p} 0)$ : island, $\ln ($ size $), \ln ($ distance to main destination) * significant at $10 \%$;* significant at $5 \%$; ** significant at $1 \%$ 
Dynamics. We supplement our cross sectional evidence by running a dynamic model of fertility. The unavailability of migration data for periods prior to 2000 prevents us to estimate a panel regression model. Nevertheless, it might be interesting to estimate a model linking the change in fertility rates with the distance between the prevailing fertility rate and the fertility rate at destination. Introducing inertia in a dynamic model makes the implications of our results stronger, for instance in terms of convergence. Since the fertility norm validated by our cross sectional analysis is $\log \left(\bar{n}^{d}\right)$, we run the following regression:

$$
\begin{aligned}
\ln \left(n_{t+1}\right)-\ln \left(n_{t}\right)= & a_{0}+a_{1} \cdot\left[\ln \left(n_{t}\right)-\ln \left({\overline{n_{t}}}^{d}\right)\right]+a_{2} \cdot \ln \left(p_{0, t}\right) \\
& +a_{3} \cdot \ln \left(S_{t}\right)+a_{4} \cdot \ln \left(R_{t}\right)+\varepsilon
\end{aligned}
$$

The key coefficient is $a_{1}$. Our model of transfer of norms implies $a_{1}<0$ : countries with fertility rates higher (resp. lower) than their fertility at destination are expected to see a decrease (resp. increase) in their fertility rate. We use the change in fertility rates between 2000 and 2005 as the dependent variable. The model is estimated with OLS and involves different samples. Table 6 summarizes the main findings. The coefficient $a_{1}$ is negative and significant at the $1 \%$ level in the four samples and specifications. This confirms the existence of a $\beta$-convergence process. The average value of $a_{1}$ across the four regressions is about $-1 / 8$. Focusing on the terms in $n_{t}$ and ${\overline{n_{t}}}^{d}$, equation (20) can be rewritten as:

$$
\ln \left(n_{t+1}\right)=\left(1+a_{1}\right) \cdot \ln \left(n_{t}\right)-a_{1} \ln \left({\overline{n_{t}}}^{d}\right)+\ldots=\frac{7}{8} \cdot \ln \left(n_{t}\right)+\frac{1}{8} \ln \left({\overline{n_{t}}}^{d}\right)+\ldots
$$

Equation (21) indicates that an equal proportionate increase in the 2000 fertility rate and the 2000 fertility norm raises the 2005 fertility rate by the same proportionate amount, with $7 / 8$ of that increase due to the increase in the 2000 fertility rate and $1 / 8$ due to the increase in the fertility norm. The migration rate has a positive impact on the 2000-to-2005 change in fertility rate in three of the four fertility change regressions (significant at the $1 \%$ level in two of the four regressions and at the $10 \%$ level in a third one), which seems to make more sense than the negative and significant coefficients obtained in four of the sixteen level regressions. 


\begin{tabular}{|c|c|c|c|c|}
\hline & (1) & $(2)$ & (3) & $(4)$ \\
\hline \multirow[t]{2}{*}{ Constant } & -0.014 & 0.008 & -0.050 & -0.028 \\
\hline & $(0.57)$ & $(0.37)$ & $(1.79)^{*}$ & (1.11) \\
\hline \multirow[t]{2}{*}{$\ln \left(n_{t}\right)-\ln \left({\overline{n_{t}}}^{d}\right)$} & -0.121 & -0.122 & -0.115 & -0.131 \\
\hline & $(4.73)^{* * *}$ & $(5.43)^{* * *}$ & $(4.28) * * *$ & $(5.34)^{* * *}$ \\
\hline \multirow[t]{2}{*}{$\ln \left(p_{0, t}\right)$} & 0.019 & 0.015 & 0.029 & 0.021 \\
\hline & $(1.67)^{*}$ & $(1.54)$ & $(4.16)^{* * *}$ & $(3.05)^{* * *}$ \\
\hline \multirow[t]{2}{*}{$\ln \left(S_{t}\right)$} & -0.002 & -0.014 & 0.009 & -0.002 \\
\hline & $(0.19)$ & $(1.44)$ & $(1.53)$ & $(0.41)$ \\
\hline \multirow[t]{2}{*}{$\ln \left(R_{t}\right)$} & & & -0.009 & -0.008 \\
\hline & & & $(2.04)^{* *}$ & $(1.89)^{*}$ \\
\hline Observations & 153 & 192 & 119 & 146 \\
\hline R-squared & 0.18 & 0.24 & 0.30 & 0.33 \\
\hline
\end{tabular}

Policy implications. The findings presented here have policy implications for both source countries in the South and host countries in the North.

Developing countries experiencing rapid population growth have typically looked at migration as one of the means of reducing population pressure and thus of reducing any social, economic and political problems associated with it. This paper has shown that South-North migration can also lead to a reduction in fertility rates, and thus to a more permanent reduction in population pressure in the South, by serving as a channel for the transfer of low-fertility norms and by raising the incentive to acquire education.

We can infer from this that an inter-temporal substitution (or tradeoff) between present and future migration exists, with an increase in current immigration resulting in a decrease in future population pressure in the South and thus in a decrease in future immigration pressure in the North. Developed host countries would benefit by taking the inter-temporal substitution in migration into account in the design of their immigration policy. Doing so should result in a more relaxed immigration policy.

Second, developing emigration countries could achieve a greater reduction in population pressure by finding ways of directing emigrants towards the OECD countries with the lowest fertility rates. This endeavor should be made easier by the fact that such countries would be likely to be more open to immigration than countries with higher fertility rates. 


\section{Conclusion}

Though numerous studies have examined the impact of migration on the fertility of migrants and their household, this paper is the first one to provide a systematic analysis of the impact of migration on fertility in migrants' home countries. Its main objective was to identify migration's impact on the transfer of destination countries' norms to migrants' home countries and hence its impact on home countries' fertility rates.

The paper first provided a theoretical analysis of the various channels through which international migration might impact fertility in migrants' home country. The model shows that migration raises adults' incentive to invest in their and their children's education and thus reduces fertility, that it raises remittance levels and that these have an ambiguous impact on fertility, and that the transfer of norms from low(high-) fertility destination countries reduces (raises) fertility in migrants' countries of origin.

The model's predictions are supported by the empirical results. Regarding the transfer of norms, we found that a one percent increase in the fertility norm to which migrants are exposed reduces home country fertility by about 0.3 percent for developing countries as well as for all countries. Thus, migration from high-fertility home countries to low-fertility destination countries reduces fertility in the former ones.

The findings presented here have a number of policy implications. Developing countries' authorities that have experienced rapid population growth continue to be greatly concerned with the potential social, economic and political problems associated with it. These countries have typically looked at migration as one of the (static) ways of reducing population pressure. This paper has shown that South-North migration can lead to a reduction in fertility rates and thus contribute to a reduction in home country population pressure by serving as a channel for the transfer of lowfertility norms and by raising the incentive to acquire education.

The tradeoff implicit in the impact of migration on fertility should be taken into account by developed host countries since accepting more migrants in the short run may reduce the migration pressure in the long run. Moreover, emigration countries could achieve a greater reduction in population pressure by finding ways of directing emigrants towards the OECD countries with the lowest fertility rates. These countries are also likely to be more open to migration than those with higher fertility.

Finally, we should note that further research of various aspects of this issue is on our research agenda - including possible differences in the home country fertility impact of a transfer of host country norms by men and by women, and differences in that impact for fertility norms that are higher or lower than the home country fertility -, and we hope that this paper will trigger other people's interest in contributing to the research effort in this area. 


\section{References}

- Beine, M., F. Docquier and H. Rapoport (2001), "Brain drain and economic growth: theory and evidence", Journal of Development Economics, 64(1), 275289

- Beine, M., F. Docquier and H. Rapoport (2008), "Brain Drain and Human Capital Formation in Developing Countries: Winners and Losers", Economic Journal, 118(528), 631-652.

- Ben-Porath, Y. (1973), "Economic Analysis of Fertility in Israel: Point and Counterpoint", Journal of Political Economy 81(2): 202-233.

- Brockeroff, M. (1995), "Fertility and Family-planning in African Cities: the Impact of Female Migration." Journal of Biosocial Science 27(3): 347-358.

- Chen, Hung-Ju (2006), "International migration and economic growth: a source country perspective", Journal of Population Economics, 19: 725-748.

- De la Croix, D. and M. Doepke (2003), "Inequality and growth: why differential fertility matters", American Economic Review, 93(4): 1091-1113.

- De la Croix, D. and M. Doepke (2004), "Private versus public education when differential fertility matters", Journal of Development Economics, 73(2): 607629.

- Docquier, F., O. Faye, P. Pestieau (2008), "Is migration a good substitute for education subsidies?", Journal of Development Economics 86, 263-276.

- Docquier, F., B. L. Lowell and A. Marfouk (2007), "A Gendered Assessment of the Brain Drain," IZA Discussion Papers 3235, Institute for the Study of Labor (IZA).

- Ebanks, E., P.M. George, C. E. Nobbe (1975), "Emigration and Fertility Decline: The Case of Barbados." Demography 12(3): 431-445.

- Farber, S.C. and B.S. Lee (1984), "Fertility Adaptation of Rural-to-Urban Migrant Women: A Method of Estimation Applied to Korean Women." Demography 21(3): 339-345.

- Fargues, Ph. (2007), "The demographic benefit of international migration: a hypothesis and its application to Middle Eastern and North African countries", in: Ozden, C. and M. Schiff (eds), International migration, economic development and policy, World Bank and Palgrave Macmillan: Washington DC. 
- Freedman, R. and D. P. Slesinger (1961), "Fertility Differentials for the Indigenous Non-Farm Population of the United States." Population Studies 15(2): 161-173.

- Galor, O. and A. Mountford (2006), "Trade and the great divergence: the family connection". American Economic Review, 96(2): 299-303.

- Goldberg, D. (1959), "The Fertility of Two-Generation Urbanites." Population Studies 12(3): 214-222.

- Goldberg, D. (1960), "Another Look at the Indianapolis Fertility Data." Milbank Memorial Fund Quarterly 38(1):23-36.

- Goldstein, S. (1978) "Migration and Fertility in Thailand, 1960-1970." Canadian Studies in Population 5: 167-180.

- Goldstein, S. and A. Goldstein (1981), "The Impact of Migration on Fertility: An 'Own Children' Analysis for Thailand." Population Studies 35(2): 265-284.

- Gould, D.M. (1994), "Immigrant Links to the Home Country: Empirical Implications for U.S. Bilateral Trade Flows," Review of Economics and Statistics, 76: $302-16$.

- Hervitz, M.H. (1985), "Selectivity, Adaptation, or Disruption? A Comparison of Alternative Hypotheses on the Effects of Migration on Fertility: The Case of Brazil." International Migration Review 19(2): 292-317.

- Hiday, V.A. (1978), "Migration, Urbanization, and Fertility in the Philippines." International Migration Review 12(3): 370-385.

- Javorcik, B., C. Özden, M. Spatareanu and C. Neagu (2006) "Migrant Networks and Foreign Direct Investment." World Bank Working Paper no. 4046. Washington DC.

- Katav-Herz, Shirit (2003), "A Model of Parental Demand for Child Labor with High Fertility Norms", Review of Economics of the Household, 1(3): 219-233.

- Kugler, M. and H. Rapoport (2006), "Skilled Emigration, Business Networks and Foreign Direct Investment." Economic Letters.

- Kulu, H (2003), "Post-war Immigration to Estonia: A Comparative Perspective," in R. Ohliger, K. Schönwälder and T. Triadafilopoulus (eds.) "European Encounters, 1945-2000: Migrants, Migration and European Societies since 1945." Aldershot: Ashgate, pp. 38-52. 
- Lee, B.S. and L.G. Pol (1993), "The Influence of Rural-Urban Migration on Migrants Fertility in Korea, Mexico and Cameroon." Population Research and Policy Review 12(1): 3-26.

- Lee, B.S. and S.C. Farber (1985), "The Influence of Rapid Rural-Urban Migration on Korean National Fertility Levels." Journal of Development Economics $17: 47-71$.

- Lindstrom, D.P. and S. Giorguli Saucedo (2002), "The Short- and Long-Term Effects of U.S. Migration Experience on Mexican Women's Fertility." Social Forces 80(4): 1341-1368.

- Lindstrom, D.P. and Munoz-Franco (2005), On contraceptives

- Lopez, R. an M. Schiff (1998), Migration and the Skill Composition of the Labor Force: the Impact of Trade Liberalization in LDCs, Canadian Journal of Economics, 31(2), 318-336.

- Martine, G. (1975), "Migrant Fertility Adjustment and Urban Growth in Latin America." International Migration Review 9(2): 179-191.

- Mayda, A.M. (2007), International Migration: a Panel data Analysis of the Determinants of Bilateral Flows, Georgetown University Working paper.

- Moav, O. (2005), "Cheap children and the persistence of poverty," Economic Journal, 115: 88-110.

- Mountford, A (1997), "Can a Brain Drain Be Good for Growth in the Source Economy", Journal of Development Economics 53 (2): 287-303.

- Mountford, A. and H. Rapoport (2007), "The brain drain and the world distribution of income and population", Discussion paper n. 04/07, CReAM, University College London.

- Myers, G.C. and E. W. Morris (1966), "Migration and Fertility in Puerto Rico." Population Studies 20(1): 85-96.

- Park, J.Y. and I.H. Park (1976), "Migration and Female Labor Force Impact on Korean Fertility. "In "Dynamics of Migration: Internal Migration and Fertility." Occasional Monograph Series Vol. 1 No. 5 Interdisciplinary Communications Program, Smithsonian Institution.

- Parsons, C.R., R. Skeldon, T.L. Walmsley and L.A. Winters (2007), "Quantifying International Migration: A Database of Bilateral Migrant Stocks", in: Ozden, C. and M. Schiff (eds), International migration, economic development and policy, World Bank and Palgrave Macmillan: Washington DC. 
- Rauch, James (2001), "Business and Social Networks in International Trade," Journal of Economic Literature 39: 1177-1203.

- Rauch, James and Vitor Trinidade (2002), "Ethnic Chinese Networks In International Trade," Review of Economics and Statistics 84(1): 116-130.

- Rosenzweig, M.R and T.P. Schultz (1985), "The Demand for and Supply of Births: Fertility and its Life Cycle Consequences", American Economic Review 75(5): $92-105$.

- Sato, Y. and K. Yamamoto (2005), "Population Concentration, Urbanization, and Demographic Transition", Journal of Urban Economics 58(1): 45-61.

- Sato, Y. (2007) "Economic Geography, Fertility and Migration", Journal of Urban Economics 61(2): 372-387.

- Spilimbergo, A. (2008), Democracy and foreign education, American Economic Review, forthcoming.

- Stephen, E.H. and F.D. Bean (1992), "Assimilation, Disruption and the Fertility of Mexican-origin Women in the United States." International Migration Review 26(1): $67-88$.

- Umezaki, M. and R. Ohtsuka (1998), "Impact of Rural-Urban Migration on Fertility: A Population Ecology Analysis in the Kombio, Papua New Guinea." Journal of Biosocial Science 30(3): 411-422.

- White, M.L., L. Moreno, and S. Guo (1995), "The Interrelation of Fertility and Geographic Mobility in Peru: a Hazards Model Analysis." International Migration Review. 29(2): 492-514. 


\section{Appendix}

\subsection{Analytics of section 3.1}

We solve the model in two steps and proceed backwards. First, for a given location, parents choose their optimal number of children. Second, after substituting this number in the utility function, parents decide how much to invest in education taking into account the endogenous probability of emigrating.

In the case of migration, the 'conditional' utility function is given by

$$
U_{t}^{f}=\log \left[\left(1-E_{t}-\phi n_{t}\right) A E_{t}^{\sigma} \bar{h}^{1-\sigma} w^{f}\right]+\beta \log \left[n_{t}\right]+C .
$$

where the constant term $C$ stands for the given levels of human capital and expected wage of their children.

The optimal fertility rate is equal to

$$
n_{t}^{*}=\frac{\beta(1-E)}{(1+\beta) \phi}
$$

and is clearly decreasing with the time spent by adults in higher education (before having children). Substituting the optimal fertility rate in the utility function gives the quasi-indirect utility function which depends on parents' education choice:

$$
V_{t}^{f}\left(E_{t}\right)=(1+\beta) \log \left(1-E_{t}\right)+\sigma \log \left(E_{t}\right)+\log \left(w^{f}\right)+\Gamma
$$

where $\Gamma \equiv \beta \log \left[\frac{\beta}{(1+\beta) \phi}\right]-\log (1+\beta)+\log (A)+(1-\sigma) \log (\bar{h})+C$ is a constant.

In the case of staying, their conditional utility function is given by

$$
U_{t}^{h}=\log \left[\left(1-E_{t}-\phi n_{t}\right) A E_{t}^{\sigma} \bar{h}^{1-\sigma}\right]+\beta \log \left[n_{t}\right]+C
$$

The optimal fertility rate is identical to the one of migrants and the quasi-indirect utility function becomes

$$
V_{t}^{h}\left(E_{t}\right)=(1+\beta) \log \left(1-E_{t}\right)+\sigma \log \left(E_{t}\right)+\Gamma
$$

Agents then maximize the expected utility function, $\left(1-p_{t}\right) V_{t}^{h}+p_{t} V_{t}^{f}$. The choice of higher education solves the following optimization problem

$$
\left\{E_{t}\right\}=\arg \max (1+\beta) \log \left(1-E_{t}\right)+\sigma\left[1+p_{0} \log \left(A \bar{h}^{1-\sigma} w^{f}\right)\right] \log \left(E_{t}\right)
$$

The optimal investment in higher education is given by

$$
E_{t}^{*}=\frac{\sigma\left[1+p_{0} \log \left(w^{f}\right)\right]}{1+\beta+\sigma\left[1+p_{0} \log \left(A \bar{h}^{1-\sigma} w^{f}\right)\right]}
$$




\subsection{Analytics of section 3.2}

The optimization problem for remaining adults can thus be written as following:

$$
\left\{n_{t}, e_{t}\right\}=\arg \max \left\{\log \left[\left(1-\phi n_{t}\right) H_{t}-n_{t} e_{t}\right]+\beta \log \left[n_{t} e_{t}^{\gamma}\left(1+\omega p_{0} e_{t}^{\gamma}\right)\right]\right\}
$$

The first order conditions (with respect to $n_{t}$ and $e_{t}$ ) can be expressed as

$$
\begin{aligned}
\frac{\phi H_{t}+e_{t}}{\left(1-\phi n_{t}\right) H_{t}-n_{t} e_{t}} & =\frac{\beta}{n_{t}} \\
\frac{n_{t}}{\left(1-\phi n_{t}\right) H_{t}-n_{t} e_{t}} & =\frac{\beta \gamma}{e_{t}}+\frac{\beta \omega p_{0} \gamma e_{t}^{\gamma-1}}{1+\omega p_{0} e_{t}^{\gamma}}
\end{aligned}
$$

The first condition is standard and implies that the total cost of children (raising cost + education) is proportional to the parent's maximal wage at the equilibrium

$$
n_{t}\left(\phi H_{t}+e_{t}\right)=\frac{\beta}{1+\beta} H_{t}
$$

This implies

$$
n_{t}^{*}=\frac{\beta H_{t}}{(1+\beta)\left(\phi H_{t}+e_{t}\right)},
$$

i.e. fertility decreases with children's education for a given parental income.

Combining the conditions yields an implicit polynomial solution for the optimal investment in education

$$
(1-2 \gamma) \omega p_{0} e_{t}^{\gamma+1}+(1-\gamma) e_{t}-2 \gamma \phi H_{t} \omega p_{0} e_{t}^{\gamma}-\gamma \phi H_{t}=0
$$

Assuming $\gamma=\frac{1}{2}$, the implicit function above becomes quadratic in $e_{t}$ and gives rise to an explicit solution. The optimal investment in children education becomes

$$
e_{t}^{*}=\left[\phi H_{t} \omega p_{0}+\sqrt{\left(\phi H_{t} \omega p_{0}\right)^{2}+\phi H_{t}}\right]^{2}
$$

\subsection{Analytics of section 3.3}

In the first sub-case, we assume that remittances $r_{t}$ are received by young parents. The optimization problem of remaining adults can thus be written as the following

$$
\left\{n_{t}, e_{t}\right\}=\arg \max \left\{\log \left(\left[\left(1-\phi n_{t}\right) H_{t}-n_{t} e_{t}+r_{t}\right]+\beta \log \left[n_{t} e_{t}^{\gamma}\left(1+\omega p_{0}\right)\right]\right\}\right.
$$

The first order conditions (with respect to $n_{t}$ and $e_{t}$ ) can be expressed as

$$
\begin{aligned}
\frac{\phi H_{t}+e_{t}}{\left(1-\phi n_{t}\right) H_{t}-n_{t} e_{t}+r_{t}} & =\frac{\beta}{n_{t}} \\
\frac{n_{t}}{\left(1-\phi n_{t}\right) H_{t}-n_{t} e_{t}+r_{t}} & =\frac{\beta \gamma}{e_{t}}
\end{aligned}
$$


As usual, the optimal cost of children is proportional to the parent's maximal income

$$
n_{t}\left(\phi H_{t}+e_{t}\right)=\frac{\beta}{1+\beta}\left(H_{t}+r_{t}\right) .
$$

Combining the first order conditions yields the following explicit solution for human capital investments

$$
e_{t}^{*}=\frac{\gamma \phi H_{t}}{1-\gamma}
$$

and for the fertility rate

$$
n_{t}^{*}=\frac{\beta(1-\gamma)\left(1+\frac{r_{t}}{H_{t}}\right)}{(1+\beta) \phi}
$$

In the second sub-case, we assume that working-aged children transfer a fraction $\tau$ of their income to their parents. Parents also receive other remittances $r_{t+1}^{o}$ from extra-family members when old, the utility function would become:

$$
U_{t}=\log \left(c_{t}\right)+\beta \log \left(\tau \widetilde{w}_{t+1} h_{t+1} n_{t}+r_{t+1}^{o}\right)
$$

Adults' optimization problem can thus be written as the following

$$
\left\{n_{t}, e_{t}\right\}=\arg \max \left\{\log \left(\left[\left(1-\phi n_{t}\right) H_{t}-n_{t} e_{t}\right]+\beta \log \left[\tau n_{t} e_{t}^{\gamma}\left(1+\omega p_{0}\right)+r_{t+1}^{o}\right]\right\}\right.
$$

The first order conditions (with respect to $n_{t}$ and $e_{t}$ ) can be expressed as

$$
\begin{aligned}
\frac{\phi H_{t}+e_{t}}{\left(1-\phi n_{t}\right) H_{t}-n_{t} e_{t}} & =\frac{\tau \beta e_{t}^{\gamma}\left(1+\omega p_{0}\right)}{r_{t+1}^{o}+\tau n_{t} e_{t}^{\gamma}\left(1+\omega p_{0}\right)} \\
\frac{n_{t}}{\left(1-\phi n_{t}\right) H_{t}-n_{t} e_{t}} & =\frac{\beta \gamma n_{t} \tau e_{t}^{\gamma-1}\left(1+\omega p_{0}\right)}{r_{t+1}^{o}+\tau n_{t} e_{t}^{\gamma}\left(1+\omega p_{0}\right)}
\end{aligned}
$$

Combining the first order conditions yields the following explicit solution

$$
e_{t}^{*}=\frac{\gamma \phi H_{t}}{1-\gamma}
$$

and for the fertility rate,

$$
n_{t}^{*}=\frac{\beta(1-\gamma)}{1+\beta}-\frac{r_{t+1}^{o}}{(1+\beta) \tau e_{t}^{\gamma}\left(1+\omega p_{0}\right)}
$$

\subsection{Analytics of section 3.4}

The optimization problem of non-migrant adults becomes

$$
\left\{n_{t}, e_{t}\right\}=\arg \max \left\{\log \left(\left[\left(1-\phi n_{t}\right) H_{t}-n_{t} e_{t}\right]+\beta \log \left[\left(n_{t}-\widetilde{n}_{t}\right) e_{t}^{\gamma}\left(1+\omega p_{0}\right)\right]\right\}\right.
$$


The first order conditions (with respect to $n_{t}$ and $e_{t}$ ) become

$$
\begin{aligned}
\frac{\phi H_{t}+e_{t}}{\left(1-\phi n_{t}\right) H_{t}-n_{t} e_{t}} & =\frac{\beta}{n_{t}-\widetilde{n}_{t}} \\
\frac{n_{t}}{\left(1-\phi n_{t}\right) H_{t}-n_{t} e_{t}} & =\frac{\beta \gamma}{e_{t}}
\end{aligned}
$$

From the second condition, we can easily derive the optimal investment in children education as a function of the fertility rate

$$
e_{t}=\frac{\gamma \phi H_{t}\left(n_{t}-\widetilde{n}_{t}\right)}{n(1-\gamma)+\widetilde{n} \gamma}
$$

Substituting this equation in the first conditions gives, after straightforward manipulations, a quadratic implicit function in $n_{t}$ :

$$
\phi(1+\beta) n_{t}^{2}-\left[\phi \widetilde{n}_{t}+\beta(1-\gamma)\right] n_{t}-\beta \gamma \widetilde{n}_{t}=0
$$

The single positive root of this equation is the optimal fertility rate:

$$
n_{t}^{*}=\frac{\phi \widetilde{n}_{t}+\beta(1-\gamma)+\sqrt{\left[\phi \widetilde{n}_{t}+\beta(1-\gamma)\right]^{2}+4 \beta \gamma \phi(1+\beta)}}{2 \phi(1+\beta)}
$$


Département des Sciences Économiques de l'Université catholique de Louvain

Institut de Recherches Économiques et Sociales

Place Montesquieu, 3

1348 Louvain-la-Neuve, Belgique 